\title{
Soft Tissue Management in Facial Trauma
}

\author{
Tara L. Braun, BS ${ }^{1}$ Renata S. Maricevich, MD $^{1}$ \\ ${ }^{1}$ Division of Plastic Surgery, Michael E. DeBakey Department of \\ Surgery, Baylor College of Medicine, Houston, Texas \\ Semin Plast Surg 2017;31:73-79.
}

\begin{abstract}
Address for correspondence Renata S. Maricevich, MD, 6701 Fannin Street, CC 610.00, Houston, TX 77030

(e-mail: Renata.Maricevich@bcm.edu).
\end{abstract}

\begin{abstract}
Keywords

- facial trauma

- soft tissue reconstruction

- facial animal bites

- facial transplants

The management of soft tissue injury after facial trauma poses unique challenges to the plastic surgeon, given the specialized nature of facial tissue and the aesthetic importance of the face. The general principles of trauma management and wound care are applied in all cases. The management of severe injuries to the face is discussed in relation to the location and the mechanism of injury. Facial transplants have arisen in the past decade for the management of catastrophic soft tissue defects, although high morbidity and mortality after these non-life-saving operations must be considered in patient selection.
\end{abstract}

Injuries to the craniofacial region are common, accounting for $7 \%$ of all emergency department visits. ${ }^{1}$ In addition, lacerations to the face and scalp account for $\sim 50 \%$ of the wounds treated in the emergency department. ${ }^{2}$ Soft tissue injuries in the setting of facial trauma may be isolated or associated with additional injuries; damage can be limited to superficial tissues or involve deeper structures. These injuries have no gender predilection and occur at a mean age of 28 years. The common causes of soft tissue facial trauma are falls, activities of daily living, sports, violence, motor vehicle accidents, animal attacks, recreational activities, and self-inflicted injuries. ${ }^{3,4}$

\section{Immediate Evaluation and Management}

\section{Stabilization}

The patient must first be evaluated according to the Advanced Trauma Life Support Protocol and be examined for associated injuries. Unless the facial injury is causing significant hemorrhage or airway compromise, the patient is usually stabilized before facial injuries are diagnosed and treated. ${ }^{5,6}$ In the setting of severe mechanisms of injury and associated facial fractures, cervical spinal injury occurs in 1.2 to $9.7 \%$ of patients and associated head injuries occur in $45.5 \%$ of patients. ${ }^{7}$ Additional assessment should search for concomitant craniofacial and ophthalmologic injuries.

\section{History and Physical}

After initial stabilization, a focused history and physical examination will help determine the management plan. The practi- tioner should establish the time and mechanism of the injury to assess the risk of contamination and whether a crush injury occurred. The patient should also be asked about prior craniofacial surgeries and pre-existing functional deficits. ${ }^{8}$ Inquire about a history of diabetes, smoking, alcohol use, or radiation therapy; all of which have been proven to inhibit wound healing. ${ }^{9}$ When the injury or resultant soft tissue swelling is severe, photos of the patient prior to injury can help determine pre-existing facial morphology and aid in closure and future reconstruction. ${ }^{10}$ An immunization history will help determine the need for rabies or tetanus prophylaxis. ${ }^{11,12}$

The initial examination of the soft tissue is best performed when the patient is lucid enough to respond to verbal commands to allow an assessment of motor and sensory nerve function, with special attention paid to the facial and trigeminal nerves. This exam of nerve function should also be performed prior to the administration of an anesthetic. The quality of the wound is examined, along with an assessment of the lacrimal apparatus, the external auditory meatus, the facial nerve, parotid duct, the underlying bone, and the tarsal plates. ${ }^{5,8,10,13}$

\section{Early Wound Management}

After the exam, the wound is irrigated with normal saline and any debris and small foreign bodies are removed to prevent infection or traumatic tattooing. Digital agitation can help facilitate irrigation, or normal saline can be placed in a large syringe with an 18-gauge needle to increase the pressure of irrigation. When this is not enough to clean the wound, diluted hydrogen peroxide can help remove dried
Issue Theme Facial Trauma; Guest Editors: Renata S. Maricevich, MD, and Tuan A. Truong, MD
Copyright (C) 2017 by Thieme Medical Publishers, Inc., 333 Seventh Avenue, New York, NY 10001, USA Tel: +1(212) 584-4662.
DOI http://dx.doi.org/ 10.1055/s-0037-1601381. ISSN $1535-2188$. 
blood and debris, but careful use is needed because it can irritate the tissues and can be toxic to the cornea. Pulse lavage can potentially damage soft tissue and is only indicated when the wound is contaminated and prior measures have not sufficiently cleaned the wound. ${ }^{8}$ Devitalized tissue is then removed conservatively with sharp debridement while preserving as much soft tissue as possible, especially in the specialized areas of the face. ${ }^{13}$

Bleeding is controlled initially to control gross hemorrhage; then hemostasis is achieved again during and after irrigation and debridement. Direct pressure is the primary method to stop bleeding, along with the identification and tying of visible vessels. Electrocautery is reserved for when these methods fail because its use is associated with poor wound healing. 8,14

Closure of the wound should optimally occur as soon as the patient is stabilized. Closure within 12 hours, or ideally within 6 hours, lowers rates of infection, improves cosmetic outcomes, and prevents subsequent swelling from obscuring landmarks. Wounds cannot be closed immediately, however, if there is too much tension on the wound or if a complex closure is required. ${ }^{7,13}$

\section{General Concepts of Repair}

\section{Primary Closure}

Some minor facial injuries can be managed effectively with tissue approximation in the emergency department. Tissue approximation is most commonly achieved via suturing, which facilitates optimal cosmetic outcomes by allowing wound edges to be everted and accurately aligned. The tissue should be closed in layers and any exposed cartilage or bone covered with soft tissue. ${ }^{15}$ Muscle edges are realigned with a 4-0 absorbable suture. For deep dermal sutures, a 4-0 or 5-0 resorbable monofilament is appropriate. For superficial skin layers, a 5-0 to 7-0 fast-absorbing or nonresorbable monofilament, such as propylene or nylon, is used. ${ }^{5,10}$ Permanent sutures on the face are removed within 5 days to prevent track marks and reduce scarring (-Fig. 1).

Staples can be used in hair-bearing areas, and tape with or without adhesive can be used alone in subcentimeter wounds or in conjunction with sutures. Adhesives may be the fastest, easiest, and most cost-effective way to close a clean, minor wound in children or uncooperative patients. However, adhesive often gets inside the wound, preventing exact approximation of the tissue. ${ }^{5,10}$ Lacerations that can be treated in the emergency department are anesthetized using local field blocks or regional blocks. Children may also require conscious sedation if they are unable to sit still or are in too much pain during wound closure.

\section{Wound Care}

Ointment keeps the wound moist and prevents scab formation, which aids in the re-epithelialization process. Antibiotic ointment is recommended in the first 2 to 7 days, followed by ointment without antibiotics, such as petroleum jelly (-Fig. 2). ${ }^{5}$ Systemic antibiotics are generally not recommended in clean, simple wounds of the face and neck that are adequately irrigated and debrided. Systemic antibiotics should be considered in specific cases such as bite wounds, puncture wounds, the presence of foreign bodies, heavy contamination, jagged wound edges, delayed closure, and in patients who are immunocompromised or at high risk for adverse outcomes. $^{16}$

\section{Repair of Complex Facial Trauma}

Severe facial trauma can cause significant morbidity and disfiguration and poses a unique challenge to the plastic surgeon, given the specialized nature of facial tissues and importance of the face for the patient's self-esteem and personal identity. After initial stabilization and life-saving measures, focus turns to a reconstructive process that aims to provide acceptable functional and aesthetic outcomes for the patient. ${ }^{17}$

\section{General Principles}

There are many methods available to import tissue to the head and neck region; the management plan is individualized to the case at hand. Local tissue flaps have limited amounts of tissue and a modest vascular supply, and thus are often saved for the final stages of reconstruction for minor contouring. Pedicled myocutaneous flaps offer large amounts of tissue with reliable vascularity for soft tissue

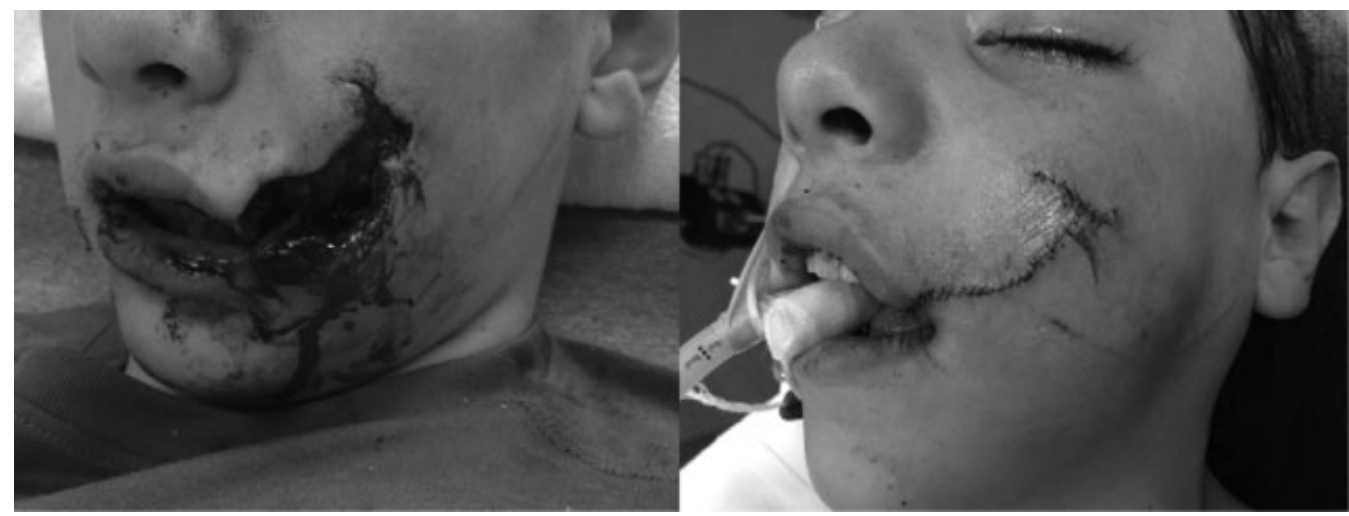

Fig. 1 Full-thickness defect of lip and cheek repaired primarily. 


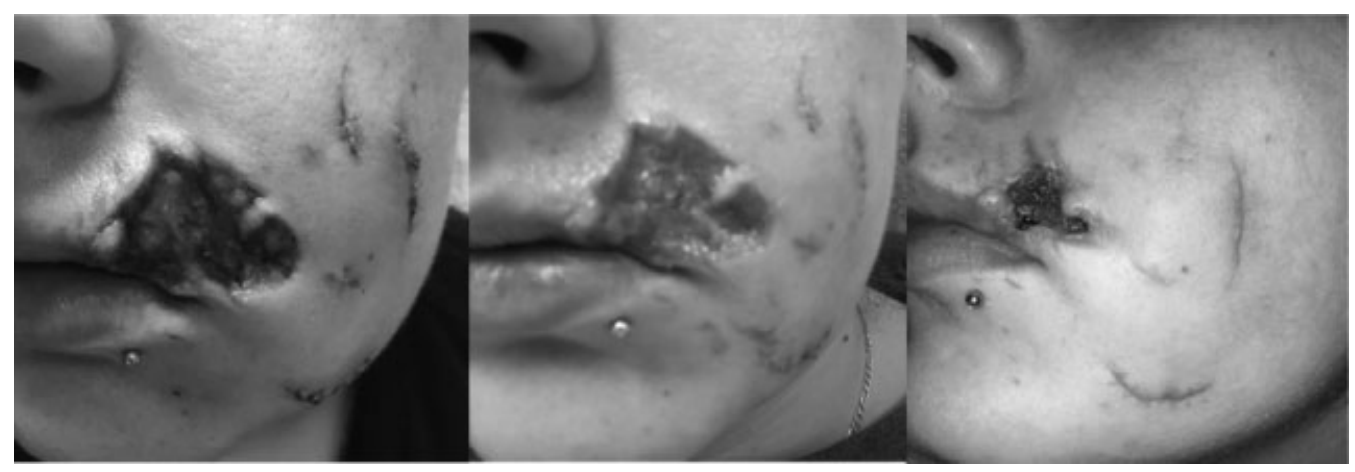

Fig. 2 Serial pictures of upper-lip defect treated with dressing changes for 6 weeks.

coverage, but are often bulky and are limited by the length of the vascular pedicle. Free tissue transfer allows the early reconstruction of damaged bones and provides soft tissue coverage soon after injury. ${ }^{18}$ Additional reconstructive techniques and tools include implants, tissue expanders, and epidermal skin grafting, although these are not frequently used in the acute setting. ${ }^{17}$

\section{Timing of Repair}

At the initial encounter, after stabilization and the management of life-threatening injuries, the initial reconstruction in the operating room serves to debride the wound, establish proper occlusion, and close the wound in the best way possible. The timing of definitive reconstruction is currently a topic of debate. Some authors suggest that, when possible, patients requiring free-tissue transfer should have their definitive treatment performed immediately (within $24-48$ hours). ${ }^{10}$ Immediate definitive reconstruction leads to fewer revisionary procedures and improved results, whereas delayed reconstruction has an increased incidence of wound contracture. ${ }^{19-21}$ Others suggest providing conservative coverage in the acute setting, then performing more lengthy definitive reconstructions after the patient has been stabilized. ${ }^{18,22}$

\section{Anatomical Considerations}

Severe facial trauma often involves multiple aesthetic units of the face. Reconstruction should ideally be planned within each facial aesthetic unit because human facial perception is based on a feature-by-feature analysis. ${ }^{23}$

\section{Scalp}

Scalp injuries are often associated with heavy bleeding due to the rich vascular network that supplies the area. After hemostasis is obtained, the wound should be examined and any lacerations smaller than $3 \mathrm{~cm}$ closed primarily; larger wounds may also require scoring of the galea to allow for primary closure. Large defects require hair-bearing tissue for reconstruction. When the wound is closed, tissue expansion is a powerful tool to create more local tissue. When an open defect is present, the reconstruction options include the local rotation advancement flaps, skin grafting, and pedicled or free flaps. ${ }^{10}$

\section{Forehead}

Though forehead reconstruction is similar to that of the scalp, the forehead is a prominent aesthetic unit of the face and thus care must be taken to ensure the proper approximation of skin tension lines, hairlines, and eyelid margins. Tissue expansion allows proper color and tissue matching that cannot be afforded by skin grafting, although sometimes skin grafting is used for temporary tissue closure in near-complete forehead defects until tissue expansion can be performed. ${ }^{10,24}$

\section{Periorbita}

Trauma to the eyelids and periorbita should prompt a thorough assessment of the globe for penetrating injuries. Simple lacerations are closed in layers from the inside out (conjunctiva, tarsus, and then skin). When the lid margin is involved, the gray line and tarsal plate should be carefully approximated. Full-thickness lid defects may be closed primarily when less than $50 \%$ of the eyelid is affected; a lateral canthotomy with cantholysis may help relieve tension in this setting. Partial-thickness defects involving more than $50 \%$ of the eyelid require a full-thickness skin graft, whereas those involving less than $50 \%$ of the eyelid can be reconstructed with local advancement flaps. Damage to the lateral eyelid often involves the lateral canthus, which can be repaired with a canthopexy or canthoplasty. Damage to the medial eyelid may involve damage to the medial canthal tendon and/ or lacrimal system, and is also often associated with fractures to this region. Canthal attachments are fixated as needed and an ophthalmologic assessment is required for injuries to the lacrimal system. ${ }^{5,10}$

\section{Lips}

In the reconstruction of the lip, the realignment of anatomical landmarks must be considered, and muscle and sensory function restored. When less than $30 \%$ of the lip is involved, primary closure can be attempted. Skin grafting and local advancement flaps are also options for management, although the best option to restore form and function to the lip is to reconstruct the defect with available lip tissue. $^{10}$

Traumatic amputation of the upper and/or lower lip, while uncommon, can result from facial animal bites, assault, or other traumatic accidents. Given that the lip is 
a specialized facial structure, lip replantation, when possible, is the best way to restore its form and function. The small caliber of the superior and inferior labial artery and vein make lip replantation difficult, and venous outflow often becomes an issue. ${ }^{25}$

During the initial surgical exploration of the amputated lip, the identification and anastomosis of suitable vessels is attempted. Successful reports of lip replantation in the literature have anastomosed the artery and vein, artery only, ${ }^{26}$ vein only, ${ }^{27}$ or have attached the artery to the vein for a "flow-through" replant ${ }^{28}$ for venous outflow.

Even a loose inset of the lip segment may lead to compromised blood flow, so delayed insets, partial delayed insets, or further loosening of the inset may be necessary to prevent or manage congestion. The majority of patients who undergo lip replantation also require leeching or chemical leeching, along with anticoagulant therapy, to aid venous outflow. When there is no venous anastomosis, it takes on average 6.6 days to relieve venous congestion, which correlates with the time needed for neoangiogenesis. ${ }^{29}$

Prophylactic antibiotics are suggested to avoid infection. Though revision procedures are often needed, many lip replants lead to the return of muscle function, stomal competence, and at least a partial return of sensation. ${ }^{26}$

\section{Ear}

Many ear injuries can be closed in the emergency department. A laceration of the auricle that involves the cartilage is reapproximated with as few sutures as possible; then the ear is monitored for hematoma formation, with pressuredressings applied when indicated. ${ }^{4}$ Small skin defects that do not involve the perichondrium are repaired with skin grafting or local flaps, and small avulsed segments can be replanted within the first 12 hours postinjury (-Fig. 3). ${ }^{8}$ Complete avulsion should be repaired immediately with microsurgical replantation, when possible. As with lip replantation, artery-only anastomosis is successful when venous drainage is provided with medicinal leeches and anticoagulation. ${ }^{30}$

\section{Facial Animal Bites}

\section{Epidemiology and Etiology}

Facial animal bites are inherently complex due to their potential for a polymicrobial infection, severe and disfiguring wounds, and subsequent psychological trauma. ${ }^{31,32}$ Mammalian bite wounds are most commonly caused by dogs, followed by cats. ${ }^{32}$ Dog bites are more common in children, with more severe injuries in children younger than 5 years. More than $80 \%$ of severe dog bites in children involve the head and neck, and most are caused by dogs that are known to the child. ${ }^{33}$

Facial dog bites are most commonly concentrated in the midface and involve the periorbita, nose, lips, and cheeks. ${ }^{34}$ Most injuries caused by dog bites are superficial, such as soft tissue lacerations (-Fig. 4). However, dog bites can also cause larger soft tissue defects as well as damage the muscles, tendons, and bones. ${ }^{34}$ The classification of facial bite injuries ranges from superficial injury without involvement of the underlying muscle to deep injuries involving the facial nerve, parotid duct, or concomitant bone fracture. ${ }^{35,36}$

Facial fractures are uncommon after dog bites, affecting $1.4 \%$ of children in one study. However, all of these patients required complex surgical repair and one-third had multiple facial fractures, so one facial fracture should prompt a careful physical exam and review of imaging for additional fractures. ${ }^{31}$ Dog bites also differ from bites from cats, rats, and humans because they are crush injuries. Therefore, they can lead to additional tissue damage via damage of the blood supply. ${ }^{37}$

\section{Management}

The early management of facial bites involves extensive wound irrigation, conservative debridement, and early primary closure: all of which improve aesthetic outcomes and reduce the risk of infection. The use of prophylactic antibiotics in facial animal bite wounds is controversial because the face is well vascularized and has a relatively low risk of infection. However, some authors suggest giving prophylactic antibiotics in all cases. Penicillin or Augmentin

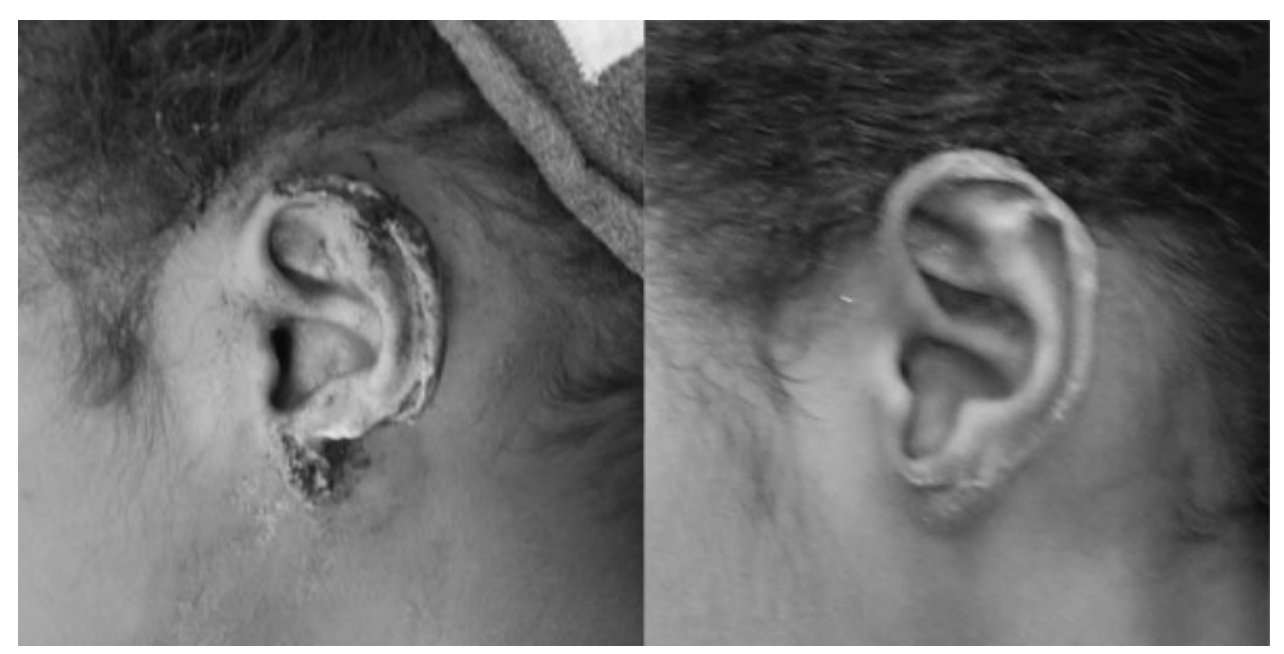

Fig. 3 Soft tissue defect of left ear with exposed cartilage, reconstructed with local tissue and postauricular flap. 


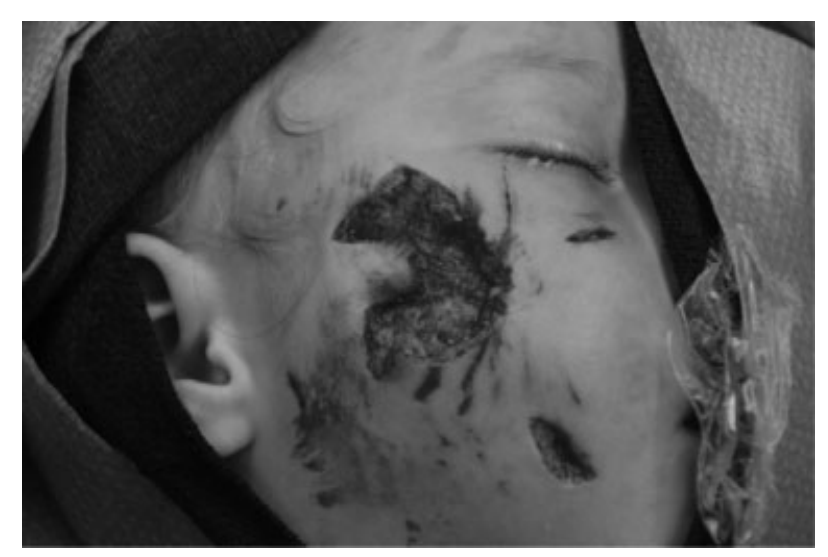

Fig. 4 Large cheek soft tissue defect on a small child secondary to a dog bite.

are preferred, or clindamycin if the patient has a penicillin allergy. $^{8,20}$

The surgical management of animal bites depends on the complexity and severity of the wound. Lackmann et al suggested a clinical classification of dog bite injuries with therapeutic guidelines for each injury stage. Stage I injuries are superficial without muscle involvement and can generally be repaired under local anesthesia, with some cases requiring conscious sedation. Stage II injuries are deeper injuries involving the muscle, often requiring hospitalization and surgical repair under general anesthesia. Stage III and IV injuries have tissue defects; their management also requires surgical treatment under general anesthesia. Repair of stage III or IV injuries additionally requires skin grafts, pedicled flaps, skeletal procedures, or microsurgical repair of the vasculature. ${ }^{36,37}$

\section{Facial Gunshot Wounds}

\section{Epidemiology and Etiology}

Gunshot wounds to the face occur at a mean age of 27 years and affect men more frequently than women. ${ }^{13}$ These injuries are often caused by an assault, an accident, or a suicide attempt. ${ }^{22}$ The entry site suffers a crush injury; then the path of the projectile creates a permanent cavity. The pressure shock wave from the projectile also creates a temporary cavity that damages the nearby microvasculature. ${ }^{5}$ Some bullets are designed to fragment upon hitting the body, causing multiple tracks and more extensive damage. ${ }^{17}$

Gunshot injuries create large defects in soft tissue and bone, and often injure numerous facial structures including the eye, tongue, cheek, lip, and palate. Additional injuries to the brain, the great vessels of the neck, the pharynx, and the larynx may occur and require immediate attention. Injury to remote organs is also possible. ${ }^{38}$

\section{Acute Nonsurgical Management}

Initial management of facial gunshot wounds follows advanced trauma life support protocols. Bleeding is controlled via the careful clamping of vessels, direct pressure, and packing. When these methods do not stop the bleeding and damage to branches of the external carotid are suspected, angiographic embolization is indicated. The initial exam should look for potential threats to the airway including laryngeal injury, aspirated teeth or bones, and intraoral swelling. A neurologic exam with an assessment of mental status, including a Glasgow Coma Score, and cervical spine stabilization is critical. Careful ocular examination, detection of malocclusion, and the documentation of facial nerve deficits should also occur. Computed tomography scans are the gold standard for assessing the nature of the injury. Three-dimensional reconstruction of the skull may be needed for complex fractures, and panoramic radiographs will illustrate dental damage. ${ }^{22}$

\section{Surgical Management}

Early surgical management requires thorough decontamination and debridement with the removal of all foreign debris before the wound is closed. Debridement should still be conservative, and any questionably viable tissue should be left alone. Serial debridement should then occur every 48 hours. Next, attempts should be made to correct the facial skeleton. Internal plating is generally used unless there is severe bone comminution with minimal damage to the overlying soft tissue, in which case external fixation can be used. ${ }^{31}$ While still under discussion, defects of the midface or mandible greater than $5 \mathrm{~cm}$ should be grafted with vascularized bone from the iliac crest or fibula. ${ }^{22,39,40}$ Nonvascularized bone is sometimes used for reconstruction if the defect is then covered with well-vascularized soft tissue. ${ }^{22,41}$

As mentioned above, the timing of definitive reconstruction of severe facial trauma is still under debate. Primary closure can often be attempted after gunshot injury and facilitated with conservative undermining of the wound edges. When the soft tissue defects do not allow primary closure without significant tension, a free flap transfer is used to cover the defect; some authors suggest an early aggressive approach with 1-stage reconstruction, whereas others prefer more conservative, staged approaches. ${ }^{22,38}$

\section{Facial Transplants}

In the past decade, facial transplants have emerged as a lifechanging operation for those with massive soft tissue deficits after a severe facial injury. Causes of these injuries include ballistic trauma, neurofibromatosis, burns, vascular lesions, blunt trauma, and cancer radiation therapy. ${ }^{42}$ Facial transplants have demonstrated positive functional, aesthetic, and psychological results. ${ }^{43}$ However, these transplants are controversial because they are not life-saving operations, but carry a high risk of morbidity or mortality due to complications from the surgery or from chronic immunosuppressive therapy. $^{42}$

A 2016 review reports on 37 facial transplants since the first transplant in 2005. These procedures provide a solution to a previously unsolvable clinical problem, and revision procedures allow refinements in aesthetic and functional results. However, revisions can potentially lead to poor wound healing, infection, and vascular compromise of the allograft. ${ }^{42,44}$ 
Acute rejection is common within the first year after transplant; the first chronic rejection has recently been reported. ${ }^{45-47}$ Infection and metabolic derangements are also common, as well as a reduction in the glomerular-filtration rate from nephrotoxic immunosuppressive agents. ${ }^{48-50}$ Posttransplant malignancies may also occur due to immunosuppression and include lymphoma, skin cancer, and smooth muscle tumors. ${ }^{45}$ Unfortunately, five recipients have died since their facial transplants; four from complications of the transplant or immunosuppressive therapy, and one from suicide. $^{42}$

Lessons learned from the past decade of facial transplants include careful patient selection with inclusion of mental health and social work providers on the multidisciplinary transplant team. This helps to ensure a thorough psychiatric evaluation prior to surgery, and full patient compliance postsurgery. Careful donor selection is also imperative; immunology, viral serology, cephalometrics, and comorbidities must be considered. ${ }^{51}$

\section{References}

1 Ong TK, Dudley M. Craniofacial trauma presenting at an adult accident and emergency department with an emphasis on soft tissue injuries. Injury 1999;30(5):357-363

2 Hollander JE, Singer AJ, Valentine S, Henry MC. Wound registry: development and validation. Ann Emerg Med 1995;25(5): 675-685

3 Kraft A, Abermann E, Stigler R, et al. Craniomaxillofacial trauma: synopsis of 14,654 cases with 35,129 injuries in 15 years. Craniomaxillofac Trauma Reconstr 2012;5(1):41-50

4 Gassner R, Tuli T, Hächl O, Rudisch A, Ulmer H. Cranio-maxillofacial trauma: a 10 year review of 9,543 cases with 21,067 injuries. J Craniomaxillofac Surg 2003;31(1):51-61

5 Crecelius C. Soft tissue trauma. Atlas Oral Maxillofac Surg Clin North Am 2013;21(1):49-60

6 Perry M, Dancey A, Mireskandari K, Oakley P, Davies S, Cameron M. Emergency care in facial trauma-a maxillofacial and ophthalmic perspective. Injury 2005;36(8):875-896

7 Mithani SK, St-Hilaire H, Brooke BS, Smith IM, Bluebond-Langner $\mathrm{R}$, Rodriguez ED. Predictable patterns of intracranial and cervical spine injury in craniomaxillofacial trauma: analysis of 4786 patients. Plast Reconstr Surg 2009;123(4):1293-1301

8 García-Gubern CF, Colon-Rolon L, Bond MC. Essential concepts of wound management. Emerg Med Clin North Am 2010;28(4): 951-967

9 Hochberg J, Ardenghy M, Toledo S, Ardenghy ME, Miura Y, Schiebel F. Soft tissue injuries to face and neck: early assessment and repair. World J Surg 2001;25(8):1023-1027

10 Kretlow JD, McKnight AJ, Izaddoost SA. Facial soft tissue trauma. Semin Plast Surg 2010;24(4):348-356

11 Bailey AM, Holder MC, Baker SN, Weant KA. Rabies prophylaxis in the emergency department. Adv Emerg Nurs J 2013;35(2):110-119 , quiz 120-121

12 Miyagi K, Shah AK. Tetanus prophylaxis in the management of patients with acute wounds. J Plast Reconstr Aesthet Surg 2011; 64(10):e267-e269

13 Collins JB, Mahabir RC, Potter JK. Facial soft tissue trauma. Janies JE. Essentials of Plastic Surgery. Boca Raton, FL: Taylor \& Francis Group; 2014:315-322

14 Wu PS, Beres A, Tashjian DB, Moriarty KP. Primary repair of facial dog bite injuries in children. Pediatr Emerg Care 2011;27(9): 801-803
15 Patel KG, Sykes JM. Management of soft-tissue trauma to the face. Operative Techniques in Otolaryngology - Head and Neck Surgery 2008;19(2):90-97

16 Medel N, Panchal N, Ellis E. Postoperative care of the facial laceration. Craniomaxillofac Trauma Reconstr 2010;3(4):189-200

17 Jaiswal R, Pu LL. Reconstruction after complex facial trauma: achieving optimal outcome through multiple contemporary surgeries. Ann Plast Surg 2013;70(4):406-409

18 Futran ND, Farwell DG, Smith RB, Johnson PE, Funk GF. Definitive management of severe facial trauma utilizing free tissue transfer. Otolaryngol Head Neck Surg 2005;132(1):75-85

19 Vayvada H, Menderes A, Yilmaz M, Mola F, Kzlkaya A, Atabey A. Management of close-range, high-energy shotgun and rifle wounds to the face. J Craniofac Surg 2005;16(5):794-804

20 Gruss JS, Antonyshyn O, Phillips JH. Early definitive bone and softtissue reconstruction of major gunshot wounds of the face. Plast Reconstr Surg 1991;87(3):436-450

21 Vásconez HC, Shockley ME, Luce EA. High-energy gunshot wounds to the face. Ann Plast Surg 1996;36(1):18-25

22 Kaufman Y, Cole P, Hollier L. Contemporary issues in facial gunshot wound management. J Craniofac Surg 2008;19(2):421-427

23 Bruce V, Young A. Understanding face recognition. Br J Psychol 1986;77(Pt 3):305-327

24 Sabatino F, Moskovitz JB. Facial wound management. Emerg Med Clin North Am 2013;31(2):529-538

25 Taylor HOB, Andrews B. Lip replantation and delayed inset after a dog bite: a case report and literature review. Microsurgery 2009; 29(8):657-661

26 Walton RL, Beahm EK, Brown RE, et al. Microsurgical replantation of the lip: a multi-institutional experience. Plast Reconstr Surg 1998;102(2):358-368

27 Hirasé Y, Kojima T, Hayashi J, Nakano M. Successful upper labial replantation after 17 hours of ischemia: case report. J Reconstr Microsurg 1993;9(5):327-329

28 Jeng SF, Wei FC, Noordhoff MS. Successful replantation of a bittenoff vermilion of the lower lip by microvascular anastomosis: case report. J Trauma 1992;33(6):914-916

29 Gustafsson J, Lidén M, Thorarinsson A. Microsurgically aided upper lip replantation - case report and literature review. Case Reports Plast Surg Hand Surg 2016;3(1):66-69

30 Momeni A, Liu X, Januszyk M, et al. Microsurgical ear replantation-is venous repair necessary?-A systematic review Microsurgery 2016;36(4):345-350

31 Wei LA, Chen HH, Hink EM, Durairaj VD. Pediatric facial fractures from dog bites. Ophthal Plast Reconstr Surg 2013;29(3):179-182

32 Chhabra S, Chhabra N, Gaba S. Maxillofacial injuries due to animal bites. J Maxillofac Oral Surg 2015;14(2):142-153

33 Chen HH, Neumeier AT, Davies BW, Durairaj VD. Analysis of pediatric facial dog bites. Craniomaxillofac Trauma Reconstr 2013;6(4):225-232

34 Nagendran S, Litwin AS, Sira M, et al. Management of facial and periocular dog bites: a review of 104 cases. Eur J Plast Surg 2014; 37:595-598

35 Kesting MR, Hölzle F, Pox C, Thurmüller P, Wolff KD. Animal bite injuries to the head: 132 cases. Br J Oral Maxillofac Surg 2006; 44(3):235-239

36 Lackmann GM, Draf W, Isselstein G, Töllner U. Surgical treatment of facial dog bite injuries in children. J Craniomaxillofac Surg 1992;20(2):81-86

37 O'Brien DC, Andre TB, Robinson AD, Squires LD, Tollefson TT. Dog bites of the head and neck: an evaluation of a common pediatric trauma and associated treatment. Am J Otolaryngol 2015;36(1): 32-38

38 Hollier L, Grantcharova EP, Kattash M. Facial gunshot wounds: a 4-year experience. J Oral Maxillofac Surg 2001;59(3):277-282

39 Dalgorf D, Higgins K. Reconstruction of the midface and maxilla. Curr Opin Otolaryngol Head Neck Surg 2008;16(4):303-311 
40 Kildal M, Wei FC, Chang YM. Free vascularized bone grafts for reconstruction of traumatic bony defects of mandible and maxilla. World J Surg 2001;25(8):1067-1074

41 Kelley P, Klebuc M, Hollier L. Complex midface reconstruction: maximizing contour and bone graft survival utilizing periosteal free flaps. J Craniofac Surg 2003;14(5):779-782

42 Sosin M, Rodriguez ED. The face transplantation update: 2016. Plast Reconstr Surg 2016;137(6):1841-1850

43 Khalifian S, Brazio PS, Mohan R, et al. Facial transplantation: the first 9 years. Lancet 2014;384(9960):2153-2163

44 Mohan R, Fisher M, Dorafshar A, et al. Principles of face transplant revision: beyond primary repair. Plast Reconstr Surg 2014; 134(6):1295-1304

45 Petruzzo P, Kanitakis J, Testelin S, et al. Clinicopathological findings of chronic rejection in a face grafted patient. Transplantation 2015;99(12):2644-2650

46 Petruzzo P, Dubernard JM. The International Registry on Hand and Composite Tissue Allotransplantation. Clin Transpl 2011;247-253
47 Sosin M, Woodall J, Schultz B, et al. Evolving concepts of skin and mucosal biopsy in facial vascularized composite allotransplantation. Curr Transplant Rep 2014;1(3):197-202

48 Broyles JM, Alrakan M, Ensor CR, et al. Characterization, prophylaxis, and treatment of infectious complications in craniomaxillofacial and upper extremity allotransplantation: a multicenter perspective. Plast Reconstr Surg 2014;133(4): 543e-551e

49 BenMarzouk-Hidalgo OJ, Cordero E, Gómez-Cía T, et al. First face composite-tissue transplant recipient successfully treated for cytomegalovirus infection with preemptive valganciclovir treatment. Antimicrob Agents Chemother 2011;55(12):59495951

50 Diaz-Siso JR, Parker M, Bueno EM, et al. Facial allotransplantation: a 3-year follow-up report. J Plast Reconstr Aesthet Surg 2013; 66(11):1458-1463

51 Diaz-Siso JR, Rodriguez ED. Facial transplantation: knowledge arrives, questions remain. Lancet 2016;388(10052):1355-1356 